\title{
La política revolucionaria como espiral de gesticulaciones en el teatro de Usigli.*
}

\section{Politics of Mexican Revolution as a Spiral of Gestures in Usigli's Theatre.}

Esta obra está bajo una Licencia Creative Commons Atribución 4.0 Internacional. DOI: $10.32870 /$ sincronia.axxii.n74.13b18

\author{
Gerardo Cruz-Grunerth \\ Universidad de Santiago de Compostela \\ posthumanistbodies@gmail.com \\ (ESPAÑA)
}

\begin{abstract}
* Este trabajo se encuadra en las actividades del Proyecto de Investigación PERFORMA. El teatro fuera del teatro. Performatividades contemporáneas en la era digital (FFI2015-63746-P) (20162019). Este proyecto fue financiado con una ayuda del Ministerio de Economía y Competitividad y cofinanciado por el Fondo Europeo de Desarrollo Regional (FEDER) correspondiente al marco financiero plurianual 2014-2020
\end{abstract}

Recibido: 29/03/2018

Revisado: 24/04/2018

Aprobado: 14/06/2018

\section{RESUMEN}

El presente artículo aborda la pieza de dramaturgia El gesticulador. Pieza para demagogos en tres actos, escrita por Rodolfo Usigli en 1938, pero publicada hasta seis años más tarde y montada en 1947 en una brevísima temporada interrumpida por la censura de Estado. Aquí se considera que lo anecdótico de esta censura debe ser leído en su dimension política, al conformar una articulación más de la espiral de gesticulaciones que la obra enuncia como parte de la política nacional. El discurso usigliano será conectado, por sus propios elementos, con los cuestionamientos sobre qué es la historia y cómo hacer historia revalorando su dimensión narrativa-literaria y, por lo tanto, ficcional; como es expuesto por Peter Burke desde el Nuevo Historicismo. Pero, también, en relación con las posturas postesctucturalistas y postmodernas que sostienen el fin de las grandes narrativas, entre ellas la Historia como gran relato de la civilización. Con esto en consideración, la hipótesis de este texto sostiene que Usigli vincula la historia nacional, la política y el teatro por sus rasgos en común, éstos son evidenciados en la obra como artefactos ficcionales; dicha ficción es expuesta como una 
maquinaria gestural que antecede, produce y desplaza la verdad y, con ello, toda posibilidad de evolución social.

Palabras clave: Política mexicana. Revolución mexicana. Teatro mexicano. Gestualidad teatral. Censura de Estado. Vinculación historia-ficción.

\begin{abstract}
This article focuses in the play El gesticulador. Pieza para demagogos en tres actos, that was written by Rodolfo Usigli in 1938, and published six years later; however, this play was not stage until 1947 in a short run interrupted by the State censorship. Here I consider that the anecdotic dimension of censorship must be read in its political dimension, which connects with the articulations of a spiral of gestures expressed in the play as part of national politics. Thanks to its inner elements, Usigli's discourse will be shown as a discussion about what is history and how to produce history in a fashion that values its literary-narrative or its fictional dimension, following Peter Burke and the contributions of New Historicism. In addition, this paper will address the scope of postmodernism and poststructuralism and its consideration of the end of the grand narratives, including that of History. With all these elements in consideration, the hypothesis of this article states that Usigli links national history, politics and theatre due to their common elements, which are evidenced in the play as fictional artifacts. That fictional device is exposed as a gestural machine that acts as antecedent, producer and destroyer of truth, and implies the elimination of any chance for social evolution.
\end{abstract}

Keywords: Mexican politics. Mexican Revolution. Mexican theatre. Theatrical gesture. State Censorship. History-fiction relationship.

La literatura de la revolución mexicana no sólo se ciñe a las obras escritas durante los años del conflicto armado, hay una serie de autores que en décadas posteriores continuaron exponiendo el movimiento social. Entre los autores que vinculan sus obras con la revolución está Rodolfo Usigli, quien en su dramaturgia El gesticulador. Pieza para demagogos en tres actos (1944) presenta una historia que no sólo depende de los sucesos previos, sino que logra engarzar dichos acontecimientos con la contemporaneidad del México en que vive. El presente ensayo se centra en la manera en que Usigli plantea la historia de la revolución y la historia de México como una producción de efectos en la vida nacional, en la cual mito, historia y teatro comparten un carácter de artefacto ficcional; así, en El gesticulador, el gesto será visto como el elemento expresivo con el cual se articulará la ficción que antecede, produce y desplaza la verdad y, con ello, elimina toda posibilidad de evolución social. 
El gesticulador es una pieza para teatro compuesta en 1938, la cual no fue publicada sino hasta 1944 y montada en 1947 en una brevísima temporada interrumpida por la censura. Esta obra ha sido abordada desde diversas perspectivas, siendo las más iluminadoras las contenidas en el libro del semiólogo de la cultura Varlos Vevia La sociedad mexicana en el teatro de Rodolfo Usigli (1990), donde hace una revisión del corpus usigliano; en este estudio, distingue las articulaciones del individuo como un "yo" frente a los demás: en aislamiento, en la vida privada y en la sociedad. En palabras de Vevia, El gesticulador adquiere una dimensión superior al resto de las obras del dramaturgo, pues en ella "encontramos la fusión de los tres círculos concéntricos en que habíamos encerrado su produción" (1990, p. 149). Lo anterior implica que, mientras que otras obras de Usigli inciden sobre cierta problematización del individuo, la que aquí se aborda representa una ejecución mucho más sofisticada en la construcción política del mexicano. A este estudio se suma el reciente artículo "Radiografía del poder del mexicano dentro de El gesticulador", donde Raúl Carrillo (2011) indaga, como Vevia, las implicaciones axiológicas individuales que se representan en la dramaturgia usugliana. En esta búsqueda por una lectura que dialogue sobre la dimensión política de la obra se encuentra el artículo de Alfredo Sosa-Velasco "La universalidad de El gesticulador" (2007), en el cual lee la pieza dramática desde la óptica de Bretch y su interés político desde y por el teatro. SosaVelasco destaca la posibilidad bretchiana de producir una necesidad de reacción en el espectador, de que, afirma, el espectador luche contra su realidad compuesta por demagogos que detentan el poder político nacional (2007, p. 35). Además, es relevante destacar el trabajo del estudioso y dramaturgo Guillermo Schmidhuber, quien en El advenimiento del teatro mexicano (1923-1938), distingue esta pieza de Usigli como la confluencia de los teatros español, mexicanista y de vanguardia, "que significó el advenimiento del teatro mexicano como teatro maduro poseedor de una estética propia" (Schmidhuber, 1989, p. 7-8).

Lo anecdótico de la censura de El gesticulador debe ser leído en su implicación política. En esta obra, el personaje principal, César Rubio, un profesor universitario de historia quien, fracasado, decide volver a su pueblo natal con su familia; pronto tiene la oportunidad de hacerse pasar por el 
héroe revolucionario que lleva su mismo nombre, el caudillo César Rubio. Con esta suplantación, en un primer momento obtiene dinero y posteriormente la oportunidad de ser gobernador y comenzar una carrera política. No es una característica accidental que Rubio sea profesor de historia, pues esto lo dota de una posición que le permite accionar y afectar en su favor la realidad histórica. El discurso de la Historia trata de fundarse en la objetividad, en la supuesta reproducción de sucesos como ocurrieron; en suma, esta disciplina adopta un carácter narrativo, pero trata de eludir cualquier vinculación con la ficcionalidad. Sin embargo, como recuerda Peter Burke: "la narración no es en historiografía más inocente de lo que es en la ficción” (1996, p. 290). Así, desde el New Historicism, se evidencia la imposibilidad de un discurso historiográfico imparcial, profundo y total; es más, estos teóricos de la historia ven en dichos factores la posibilidad para reformular el quehacer de la historiografía y la adopción de nuevas vías para su ejecución: "el número de historiadores conscientes de que su obra no reproduce lo que realmente ocurrió sino que la presenta desde una perspectiva particular aumenta progresivamente. Las formas narrativas tradicionales [de la historiografía] son inadecuadas para transmitir esta certeza" (Burke, 1996, p. 296). Así, el personaje César Rubio sabe que la escritura tradicional de la historia es un mecanismo cultural, que individuos particulares concatenan elementos para producir cierta representación y su posición como experto en la revolución mexicana le permite beneficiarse, aún cuando en el pasado su conocimiento fue infructuoso:

No hay un solo hombre en México que sepa todo lo que yo sé de la revolución [...] todo lo que sé no me ha servido de nada hasta ahora. Mi conocimiento me parece a menudo una podredumbre interior, porque no he podido crear nada con lo que sé... ni siquiera un libro. (Usigli, 1963, pp. 12-18)

No sólo se trata de su posición como historiador y de su conocimiento, sino de la llegada incidental a su casa de un historiador de la Universidad de Harvard, Oliver Bolton, quien tiene los medios para realizar lo que Rubio no pudo hacer, investigar y publicar sus hallazgos sobre la revolución. 
Además del conocimiento, César Rubio cuenta con un elemento de valor para la escritura de la historia pues posee un archivo (aunque nunca se explica qué materiales documentales contiene). Es importante recordar que el poder del archivo como constructor de la historia, como afirma Michael Chanan: "The archive constitutes a space of aporía, but also a site of potential interaction between history and public memory [El archivo constituye un espacio de aporía, pero también un sitio de posible interacción entre la historia y la memoria social]" (2007, p. 259). Aunque Chanan se refiere principalmente al archivo fílmico, la idea de montaje cobra relevancia como forma de composición de la historia, lo que se pone en juego en el texto de Usigli, luego que su personaje es capaz de utilizar dicho archivo para afectar el montaje de la historia de la revolución. Esto muestra la injerencia del individuo en la construcción historiográfica; desde luego, para el profesor César Rubio es relativamente fácil intervenir, no sólo por los materiales documentales que posee, también gracias a la coincidencia del nombre del caudillo revolucionario del cual se ha perdido el rastro desde 1914 hasta entonces. Efectivamente, César Rubio jamás asegura ser el general, pero la ambigüedad y la parcialidad de sus declaraciones ayudan a construir una nueva verdad. La revolución misma se había valido del montaje, del archivo como vía para autoficcionalizar, por ello César Rubio representa al revolucionario perfecto, aquel cuya historia es accesible y puede configurarse siguiendo la maquinaria discursiva del movimiento.

Contrario a la proliferación de imágenes de los principales caudillos de la revolución, como son Pancho Villa o Emiliano Zapata, pese a la relevancia del general César Rubio al lado de Villa y su actuar decisivo en la revolución, pareciera que su imagen, su fotografía, no ha sido difundida. Esto es comprensible por su súbita desaparición. Así, hay una ausencia de imagen y ésta parece sólo permanecer en la memoria de algunos pobladores y los viejos del pueblo. Guzmán lo reconoce: "Era yo muy joven todavía y no lo vi más que una vez; pero para mí, es él. Lo he estado observando todo este tiempo" (Usigli, 1963, p. 55) y más adelante, como último verificador, Emeterio Rocha es llevado a reconocer a Rubio: "Hace tantos años que [...] Creo que no has cambiado nada, sólo te ha crecido el bigote. Eres el mismo [...] Pues, hombre, es curioso. Pero sí es el mismo... pues sí... el 
mismo César Rubio" (1963, p. 66). Hay un desconocimiento del rostro del general, por eso la imitación es sencilla. Es, así, un gesto que se ejecuta, facilitado por la falta de referencialidad. Una vez más, este es el valor conferido a la materialidad del archivo textual o visual como vías de verificación y autentificación. La ausencia de la materialidad, del archivo textual o visual, permite que César Rubio pueda ser representado con múltiples imágenes, es decir, que pueda ser suplantado o narrativizado. Una prueba para el "general" Rubio es identificar una fotografía del abuelo de Guzmán, Rubio lo reconoce: "Es Isidro Guzmán; lo mataron los huertistas el 13, en Saltillo" (1963, p. 56). Este es el valor de conocer la historia, el poder para rearticularla a voluntad.

Los puntos anteriores, correspondientes al valor del archivo, la falta de materialidad o evidencia visual material del rostro del general rubio, el conocimiento y re-conocimiento de elementos visuales originales, se establecen como una vía de autentificación. Si bien sirven para verificar la identidad de Rubio, estos mismos elementos han funcionado en la producción cultural de la revolución, de la mitologización de sus caudillos, del heroísmo de la hazaña bélica. Han permitido formular una historia por parte de sus individuos pero también por parte de la institución, por el Estado. Como parte de los protocolos de la política, al final del segundo acto, cuando toda duda ha sido erradicada sobre si César Rubio es el general, y cuando ha accedido a representar al Partido Revolucionario de la Nación para la elección a gobernador estatal, se hace presente el fotógrafo de prensa. Este, incluso dirige la composición del cuadro, la retórica de la imagen según una práctica canonizada; así dice: “iUn momento así, mi general! (Magnesio.) Ahora una estrechando la mano del licenciado Estrella. ¡Eso es! (Magnesio.) Ahora con la familia" (Usigli, 1963, p. 67). De esta manera, la construcción de la imagen retoma la construcción del gran caudillo revolucionario para proyectarlo a la memoria social, como un eco del pasado cuando la instrucción “¡Un momento así, mi general! (Magnesio.)” era repetida y el objetivo frente a la cámara acostumbraba a alternar a la figura nacional. Esta fuerza de la imagen que crea verdad entre la colectividad, aunque no sea cierta. Rubio cuestiona si en su retrato él luce parecido. Guzmán responde: 
Ya lo creo que es parecido. El otro día, viendo un cartel, me decía uno de los viejos del pueblo, que lo conoció cuando usted empezaba en la Revolución: César no cambia; está igual que cuando le barrieron a la gente en Hidalgo, hace treinta años. (Usigli, 1963, p. 75)

Una vez más se reitera que la historia se escribe, o se produce, al generar materialidad documental y al configurarla. La literatura de la revolución mantiene un punto de reiteración, el cual consiste en el cuestionamiento sobre quién puede construir la historia de la revolución, quién puede cuestionarla e incluso despreciarla. El escritor literario, novelista o dramaturgo, parece posicionarse como uno de estos sujetos constructores del discurso cultural histórico. Dentro de sus obras, hay una frecuente aparición de sujetos superiores, educados e incluso autorreconocidos como intelectuales; ellos aparecen como testigos o como narradores de los sucesos. Por lo cual, en Los de abajo (Azuela, 1916) el personaje de Luis Cervantes, citadino, estudiante de medicina y periodista, sirve como vía para contrastar la falta de ideología del pueblo armado, la bola, y exponer su arbitrariedad. Para marcar este enfrentamiento, en El gesticulador se presenta a César Rubio como intelectualmente superior al pueblo e incluso a los gobernantes: "Sé que puedo hacer bien a mi país impidiendo que lo gobiernen los ladrones y los asesinos como tú... que tengo en un solo día más ideas de gobierno que tú en toda tu vida" (Usigli, 1963, p. 83). Como se dijo atrás, otra vía para la formulación de la historia es desde la universidad, los personajes son profesores de la Universidad de México y de la Universidad de Harvard. Finalmente, se manifiestan como artefactos para hacer la historia los elementos impresos, la prensa, el libro, el periódico, los carteles y las fotografías. El profesor estadounidense ha publicado un artículo, pero también ha sido la prensa mexicana la que ha difundido la continuidad de la historia del general Rubio; por ello, el profesor Rubio se entera de que públicamente está ligada su persona al nombre del general y que ya forman una imagen social. De esta manera, Usigli ficcionaliza dicho proceso de producir la historia.

La revolución como narrativa construida por sus propios actores ha servido para la institucionalización tanto de la historia nacional como del Estado, este último autoproclamado 
como un ente revolucionario. Es a través de la designación del nuevo partido como Partido Nacional Revolucionario en 1929, y posteriormente como Partido de la Revolución Mexicana en 1936, que se otorga a la organización política un carácter de continuadora no sólo de los ideales revolucionarios sino de la revolución misma. Asimismo, ante un escenario de orfandad de héroes que ha dejado la revolución, al eliminar sus propias figuras icónicas de la lucha, el partido y el aparato del Estado han efectuado una transposición: en el nicho vacío del caudillo revolucionario aparecerá la figura del presidente, un general que lidera la sobrevida del movimiento. El aura, ese "entretejido muy especial del espacio y tiempo: aparecimiento único de una lejanía, por más cerca que pueda estar" (Benjamin, 2003, p. 47), que porta la imagen del caudillo, o las imágenes de soldados que exaltan la revolución como movimiento social popular, es lo que ha procurado el nuevo Estado oficial mexicano al infundirle a su partido un espíritu de extensión de la lucha social y al conferírselo al primer mandatario. El mismo Usigli en el epílogo a esta obra afirma:

[...]ha calificado de revolucionarios a muchos gobiernos que, aunque encabezados por caudillos de la revolución, eran negras equivalencias de atrasadas tiranías que, en vez de objetivarse sinceramente como tales, se cubrían con la piel de la revolución -si le han dejado piel a la revolución- (1938, s. p.).

Es, una vez más, la presencia que ha ocupado la silla presidencial en la mítica fotografía donde Villa y Zapata están en Palacio Nacional. Este uso del aura revolucionaria y caudillista también condiciona a entender el movimiento bélico como un triunfo social, un triunfo del pueblo. Aunque dicha fotografía no significara el desenlace de la revolución, ella aportaba una confirmación de la utopía y, por ello, la imposibilidad de la propuesta: los campesinos como gobernantes, los campesinos en la silla presidencial. Este es el procedimiento de continuidad o sustitución del héroe que ha comenzado con las traiciones y asesinatos que involucran a Francisco I. Madero, Villa, Zapata, Carranza, y que efectuaban un acto de superposición por parte del perpetrador, como es el caso del general Victoriano Huerta. Desde el pensamiento influido por la deconstrucción, para Mark Currie estos son los efectos de una antiteleología: "the possibility of what comes later is the origin of the 
origin, so that the origin always contains within it the mark of what is to come [la posibilidad de lo que está por venir es el origen del origen, así el origen siempre contiene dentro de él la marca de lo que está por venir]" (Currie, 1998, p. 84). En la dramaturgia de Usigli, el profesor César Rubio, como se ha dicho, aprovecha su condición para ocupar el lugar de un general asesinado. El juego de suplantaciones es, en palabras del profesor Rubio, endémico al mexicano:

Puede que yo no sea el gran César Rubio. Pero ¿quién eres tú? ¿Quién es cada uno en México? Dondequiera encuentras impostores, impersonadores, simuladores; asesinos disfrazados de héroes, burgueses disfrazados de líderes; ladrones disfrazados de diputados, ministros disfrazados de sabios, caciques disfrazados de demócratas, charlatanes disfrazados de hombres. ¿Quién les pide cuentas? Todos son unos gesticuladores hipócritas. [...] Todos usan ideas que no son suyas; todos son como las botellas que se usan en el teatro: con etiqueta de coñac, y rellenas de limonada [...] Es una cosa del país. Está en toda la historia, que tú no conoces. (Usigli, 1963, pp. 82-83)

Es de esta manera como la vida del país, su historia y la ficcionalidad literaria y representación teatral son expresadas por Rubio como objetos desprovistos de verdad. Ya antes, con el carácter autoreflexivo de la obra se expuso el uso del gesto, del montaje, la teatralización que el personaje ejecuta y a la vez se discute esto mismo: "Han pasado muchos años... los hombres se transforman" (Usigli, 1963, p. 56) o al confesar: "No puedo hacer nada más que seguir, Elena; soy el eje en la rueda. Pero siento que el muerto no es César Rubio, sino yo, el que era yo" (1963, p. 89). Esta formulación es útil para mostrar la contradicción en la que el personaje va cayendo. Si se dijo atrás que el presidente como sustituto del caudillo se embestía del aura del caudillo, con Rubio al final de la obra él es la corporalidad o el recipiente del aura del caudillo. Sin embargo, el encadenamiento de sustituciones no termina con Rubio o con su ejecución. Una vez más, la obra reproduce la mecánica de la transferencia y la gesticulación. Navarro, que había sido relegado por la presencia de Rubio en los comicios y por lo tanto había perdido su valor simbólico ante el pueblo, al asistir a la 
casa de los deudos de Rubio para dar el pésame, vuelve a presentarse renovado ante el pueblo. En un alarde demagógico dice al pueblo exaltando la memoria de Rubio, construyendo la transición:

César Rubio ha caído a manos de la reacción en defensa de los ideales revolucionarios [...] Si soy electo, haré de la memoria de César Rubio, mártir de la Revolución, víctima de las conspiraciones de los fanáticos y los reaccionarios, la más venerada de todas. Siempre lo admiré como a un gran jefe. La capital del Estado llevará su nombre, le levantaremos una universidad, un monumento que recuerde a las futuras generaciones. (Usigli, 1963, p. 99)

Es también con este proyecto con que se expone de nuevo la maquinaria de la mitificación del héroe. Dicha mitificación funciona para sostener materialmente la historia, pero también para sostener al Estado institucionalizado, a su partido y a su presidente como continuadores del heroísmo revolucionario. Al final de la obra, se lee la acotación: "Sale [Navarro]. Se oye un clamor confuso afuera. Luego, voces que gritan: ¡Viva Navarro!" (Usigli, 1963, p. 101). Así, la espiral del aura revolucionaria y caudillista ha sido adoptada por un nuevo sujeto, y el pueblo la reconoce, reconoce el gesto y responde a él.

La obra de Usigli no trata de un proceso post-revolucionario, sino de una característica propia de la revolución mexicana, como una espiral de gesticulaciones, en un movimiento inacabado. El valor del gesto y lo visual es expuesto en un paratexto escrito por el mismo Usigli. En el texto que escribiera para su obra bajo el título de Epílogo sobre la hipocresía del mexicano (1938), el autor señala que el mecanismo narrativo de la historia y el ficcional en el arte dramático requieren de la voluntad de crear algo que no existe, algo para ser percibido por la colectividad:

Para comprender mejor la multiplicidad de las mentiras individuales en que se apoya la revolución, basta el espectáculo de revolucionarios divididos en pugna mortal, que tratan cada cual de colectivizar su propia mentira. A la gran mentira colectiva de todos los tiempos -la esperanza- se suma entonces en los caminos de la revolución un procedimiento destinado a inflar, a decorar y a publicar las mentiras individuales. Este procedimiento es viejo y sus raíces se hunden en la antigüedad griega. Me refiero a la 
demagogia. [...] La demagogia entre nosotros suple a la realidad, excita la actitud de creery tiende a precipitar el proceso de colectivización de las mentiras; pero no es una ni otra, sino el instrumento de todas ellas. Se anticipa a la existencia real de las cosas. (Usigli, 1938, s. p.)

Es necesario subrayar que el enfoque de Usigli expone que las voluntades individuales buscan construir o hacer presente lo incorpóreo, representarlo, mostrarlo al pueblo. Crear algo que no existe y anticiparse a la existencia de las cosas implica para Usigli la condena a una irrealidad que tendrá sus repercusiones cíclicamente. Por una parte, el movimiento revolucionario no parece carecer de una originaria necesidad popular; esta es también la lectura del historiador Allan Knight, quien afirma que "[Revolution] It required a political crisis [...] to topple the regime and allow social conflicts to come to the fore [la revolución requiere una crisis política (...) para derrocar al régimen y permitir a los conflictos sociales pasar al primer plano]" (1985, p. 22). Asimismo, el dramaturgo aporta en la obra y en su epílogo un énfasis en la continuidad revolucionaria como un efecto adverso para el pueblo e incluso como contradicción del ideal revolucionario. Sobre este punto Knight advierte:

All the structural options created by the revolution have been exhausted, that the revolution's legacy has been spent, that the outcome is now clear, fixed, immutable and unilinear. The agrarian reform was declared terminated (by Calles) in 1930; the revolution has been pronounced dead on many occasions since [Todas las opciones estructurales creadas por la revolución han sido agotadas, el legado de la revolución ha sido gastado, el resultado es ahora claro, fijo, inmutable y unidireccional. La reforma agraria se declaró terminada (por Calles) en 1930; y a la revolución se le ha considerado muerta en numerosas ocasiones desde entonces]. (1985, p. 28)

Queda claro que el proyecto que esta dramaturgia porta no es la búsqueda de una verdad esencial, sino que mantiene un propósito eminentemente político. Usigli ficcionaliza al individuo que busca 
ficcionalizarse como caudillo, lo hace para exponer la gestualidad desde lo individual hasta la política institucional del Estado. De esta manera, para el dramaturgo sí hay un legado del conflicto armado iniciado en 1910, son los efectos de la revolución, su uso durante las décadas de los años 10 a los 20, pero también sus efectos posteriores. Los efectos continuados portan así la expresión profunda de El gesticulador, donde el país, los movimientos sociales, las instituciones, los caudillos y el pueblo permanecerán sujetos a una mecánica con que la nación tropiece incesantemente, sin producir jamás la pretendida evolución social.

\section{Referencias:}

Azuela, M. (1996). Los de abajo. México: FCE.

Benjamin, W. (2003). La obra de arte en la época de su reproductibilidad técnica. México: Ítaca.

Burke, P. (1996). "La historia de los acontecimientos y renacimiento de la narración". En P. Burke (Ed.), Formas de hacer Historia (pp. 287-305). Madrid: Alianza.

Carrillo, R. (2011). Radiografía del poder del mexicano dentro de El gesticulador de Rodolfo Usigli. Literatura Mexicana 22, 141-156.

Chanan, M. (2007). The Politics of Documentary. London: British Film Institute.

Currie, M. (1998). Postmodern Narrative Theory. London: St. Martin's Press.

Knight, A. (1985). The Mexican Revolution: Bourgeois? Nationalist? Or Just a 'Great Rebellion'? Bulletin of Latin American Research 4 (2), 1-37.

Schmidhuber, G. (1989). El advenimiento del teatro mexicano (1923-1938). Años de esperanza y curiosidad. Tesis doctoral. Cincinnati: Universidad de Cincinnati.

Sosa-Velasco, A. (2007). La universalidad de El gesticulador de Rodolfo Usigli: Una lectura brechtian. Latin American Theatre Review 41, 33-51.

Usigli, R. (1963). El gesticulador. Pieza para demagogos en tres actos. New Jersey: Prentice-Hall.

--- (1938). Epílogo sobre la hipocresía del mexicano. Obtenido el 13 de enero de 2017 de http://www.cervantesvirtual.com/portales/rodolfo_usigli/obra-visor/epilogo-sobre-lahipocresia-del-mexicano/html/1d8fa99f-3851-4967-812a-dc59a3c93dc7_2.html\#l_0_

Vevia, C. (1990). La sociedad mexicana en el teatro de Rodolfo Usigli. Guadalajara: Universidad de Guadalajara. 